ARTICLE

https://doi.org/10.1038/s41467-018-08145-2

\title{
A recurrent cancer-associated substitution in DNA polymerase $\varepsilon$ produces a hyperactive enzyme
}

\author{
Xuanxuan Xing ${ }^{1,4}$, Daniel P. Kane ${ }^{1,5}$, Chelsea R. Bulock1, Elizabeth A. Moore', Sushma Sharma²,
} Andrei Chabes ${ }^{2,3} \&$ Polina V. Shcherbakova ${ }^{1}$

\begin{abstract}
Alterations in the exonuclease domain of DNA polymerase $\varepsilon$ (Pole) cause ultramutated tumors. Severe mutator effects of the most common variant, Pole-P286R, modeled in yeast suggested that its pathogenicity involves yet unknown mechanisms beyond simple proofreading deficiency. We show that, despite producing a catastrophic amount of replication errors in vivo, the yeast Pole-P286R analog retains partial exonuclease activity and is more accurate than exonuclease-dead Pole. The major consequence of the arginine substitution is a dramatically increased DNA polymerase activity. This is manifested as a superior ability to copy synthetic and natural templates, extend mismatched primer termini, and bypass secondary DNA structures. We discuss a model wherein the cancer-associated substitution limits access of the $3^{\prime}$-terminus to the exonuclease site and promotes binding at the polymerase site, thus stimulating polymerization. We propose that the ultramutator effect results from increased polymerase activity amplifying the contribution of Pole errors to the genomic mutation rate.
\end{abstract}

\footnotetext{
${ }^{1}$ Eppley Institute for Research in Cancer and Allied Diseases, Fred \& Pamela Buffett Cancer Center, University of Nebraska Medical Center, Omaha, NE 68198, USA. ${ }^{2}$ Department of Medical Biochemistry and Biophysics, Umeå University, 90187 Umeå, Sweden. ${ }^{3}$ Laboratory for Molecular Infection Medicine Sweden, Umeå University, 90187 Umeå, Sweden. ${ }^{4}$ Present address: Comprehensive Cancer Center, Ohio State University, Columbus, OH 43210, USA. ${ }^{5}$ Present address: Department of Biological and Environmental Sciences, Le Moyne College, Syracuse, NY 13214, USA. Correspondence and requests for materials should be addressed to P.V.S. (email: pshcherb@unmc.edu)
} 
$\mathrm{T}$ he fidelity of DNA replication is contingent upon the serial action of DNA polymerase selectivity, exonucleolytic proofreading, and DNA mismatch repair $(\mathrm{MMR})^{1-3}$. In eukaryotes, three replicative DNA polymerases, Pola, Pol $\delta$, and Pole, contribute to genome stability via their intrinsic nucleotide selectivity. Pol $\delta$ and Pole are additionally equipped with a proofreading exonuclease activity that can remove incorrectly inserted nucleotides from the primer terminus, further improving the fidelity of DNA synthesis. Somatic alterations in the exonuclease domain of Pole are commonly found in hypermutated colorectal and endometrial tumors, and, at a lower frequency, in other types of gastrointestinal and gynecological cancers, as well as tumors of the brain, breast, prostate, lung, kidney, and bone ${ }^{4-8}$. Germline mutations affecting the exonuclease domain of Pole cause a colorectal cancer predisposition syndrome characterized by early disease onset and multiple tumors ${ }^{9}$. Pole-mutant tumors typically have an exceptionally high mutation load and are classified as ultramutated to distinguish them from less severely hypermutated MMR-deficient tumors.

It was originally suggested that the changes in Pole promote ultramutation by disabling proofreading ${ }^{9}$. Many of the cancerassociated amino acid substitutions were predicted by in silico analysis to affect DNA binding in the exonuclease site and/or exonuclease activity. Indeed, cancer-associated variants were shown to reduce exonuclease activity and fidelity of a purified catalytic fragment of human Polk $\varepsilon^{10}$. However, several observations are difficult to reconcile with the idea that the pathogenicity of Pole variants results solely from adverse effects on proofreading. First, mutations at catalytic residues in the exonuclease domain, which are well known to inactivate proofreading, are rarely or never seen in tumors. Instead, mutations at other conserved residues appear as recurrent hotspots, the P286R substitution being by far the most common in sporadic cancers ${ }^{4}$. Second, modeling of the P286R variant in yeast produced an exceptionally strong mutator phenotype exceeding that of an exonuclease-dead Pole mutant by two orders of magnitude ${ }^{11}$. Mirroring these observations, Pole ${ }^{P 286 R}$ mice are dramatically more cancer-prone than Pole exonuclease-deficient mice ${ }^{12}$. The mutator effects of many other, less common, Pole variants also exceed the effects of exonuclease deficiency ${ }^{13}$. These observations strongly argue that the development of an ultramutated phenotype requires some functional changes in the protein distinct from a loss of proofreading. The nature of these changes and the mechanism through which the cancer-associated Pole variants elevate genome instability remain enigmatic.

In this work, we purified the yeast analog of Pole-P286R (yPole-P301R) as a four-subunit holoenzyme and demonstrated that it is not less accurate than proofreading-deficient Pole (exoPole). In fact, Pole-P301R is slightly more accurate, in line with the presence of residual exonuclease activity. At the same time, the analysis of mutational specificity and synergistic interactions with a MMR defect argues that the ultramutator effect in vivo results from a catastrophically high rate of errors made by PoleP301R during replicative DNA synthesis. We found that the major property distinguishing Pole-P301R from both the wildtype and exo ${ }^{-}$Pole is an extremely robust DNA polymerase activity. This is evident from a more efficient overall DNA synthesis and also a greatly improved ability to handle a variety of difficult DNA substrates that normally present an obstacle for Pole. Taking into account the structural insights provided by the companion study by Parkash and co-authors ${ }^{14}$, we propose that the uniquely strong pathogenic effects of this recurrent cancerassociated variant result from the arginine side chain restricting access of the primer terminus to the exonuclease active site. The inability to position the 3 -terminus in the exonuclease site makes Pole a more efficient DNA polymerase, a consequence that is not achieved by simple elimination of catalytic residues. These findings provide insight into the molecular mechanisms that drive the development of ultramutated cancers, and also have implications for understanding the normal physiological role of Pole in DNA replication and mutation avoidance.

\section{Results}

Pole-P301R is more accurate than exonuclease-deficient Pole. The mutator effect of the yeast Pole-P301R mimicking human Pole-P286R greatly exceeds that of any previously studied Pole mutation ${ }^{11}$, suggesting that the enzyme might possess some unusual novel properties. A decrease in $3^{\prime} \rightarrow 5^{\prime}$ exonuclease activity was expected from previous studies ${ }^{10}$ but would be insufficient to explain the strong mutator phenotype. We first hypothesized that the P301R substitution resulted in a more severe reduction in the enzyme's fidelity, perhaps due to a combination of the impaired proofreading with a nucleotide selectivity defect. We purified the four-subunit Pole-P301R and compared its exonuclease activity and the overall fidelity to those of the wild-type Pols and exoPole. The exo ${ }^{-}$Pole is completely devoid of exonuclease activity due to the replacement of the catalytic residues Asp290 and Glu292 with alanines ${ }^{15}$. Pole-P301R was readily purified as a four-subunit holoenzyme with the proper stoichiometry, indicating that the mutation does not affect interaction with the accessory subunits (Supplementary Fig. 1). The four-subunit Pole-P301R showed a significantly reduced but still detectable $3^{\prime} \rightarrow 5^{\prime}$ exonuclease activity in assays with a correctly matched oligonucleotide primer/template substrate (Fig. 1a), similar to previous observations with the catalytic fragment of human PoleP286R ${ }^{10}$. The exonuclease activity was mildly stimulated by the presence of a mismatched base pair at, or in the vicinity of, the primer terminus (Supplementary Fig. 2) and was the highest with a single-stranded oligonucleotide substrate (Fig. 1b). Thus, PoleP301R was clearly capable of hydrolyzing 3'-termini, although it was severely impaired in comparison to the wild-type enzyme.

Next, we characterized the fidelity of DNA synthesis by Pole$\mathrm{P} 301 \mathrm{R}$ in vitro using the M13mp2 lacZ forward mutation assay ${ }^{16}$. We previously observed that mimicking the physiological intracellular dNTP concentrations in the in vitro fidelity assays can be critical to recapitulate the mutator properties of replicative DNA polymerase variants ${ }^{17}$. We found that the sizes of dNTP pools in the wild-type strain and the yeast pol2-P301R mutant producing Pole-P301R were similar (Supplementary Fig. 3). The pol2-4 strains producing exo ${ }^{-}$Pole are also known to have wild-type dNTP levels ${ }^{18}$. Accordingly, we used dNTP concentrations calculated for wild-type S-phase yeast cells ${ }^{17}$ (see Methods) in the in vitro fidelity assay to mimic the intracellular conditions. We observed that Pole-P301R was more accurate than exo $^{-}$Pole. The lac $Z$ mutant frequencies were 0.012 and 0.032 for the two enzymes, respectively $(p<$ 0.00001 , Fisher's exact test; Fig. 1c and Supplementary Table 1). The lower error rate of Pole-P301R was in agreement with the presence of a limited exonuclease activity (Fig. 1a, b) but in striking contrast to its prodigiously higher mutator effect in vivo ${ }^{11}$. Error rates were lower in Pole-P301R reactions for all types of base-base mispairs in comparison to exo- Pole reactions, but a particularly strong difference was seen for transversion-type (pyrimidine-pyrimidine and purine-purine) mispairs (Fig. 1d; Supplementary Table 1), possibly because these are proofread more efficiently by the weak exonuclease of Pole-P301R. Notably, Pole-P301R-induced base substitutions occurred at a smaller number of sites (Supplementary Fig. 4a,b), suggesting that Pole-P301R is rather accurate at most DNA sequences, and there are only certain positions where its fidelity is compromised. Overall, the in vitro assays showed that Pole- 
a

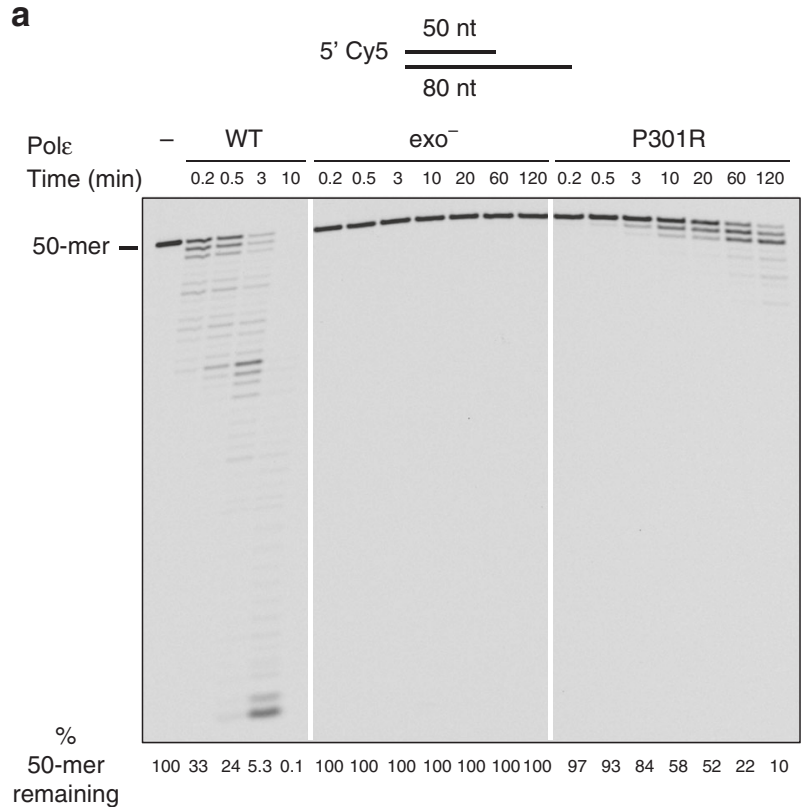

b

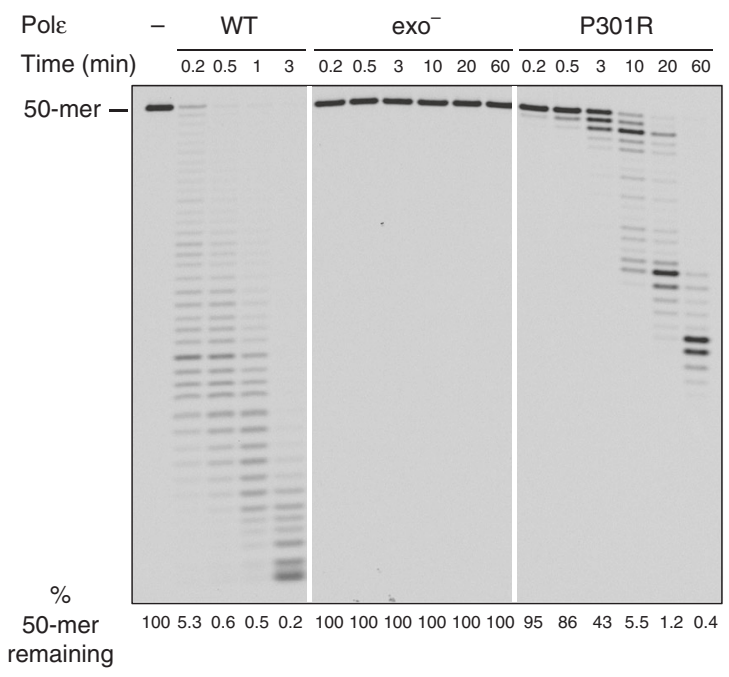

C

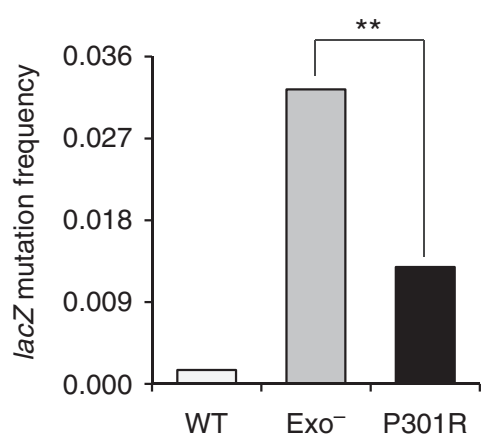

d

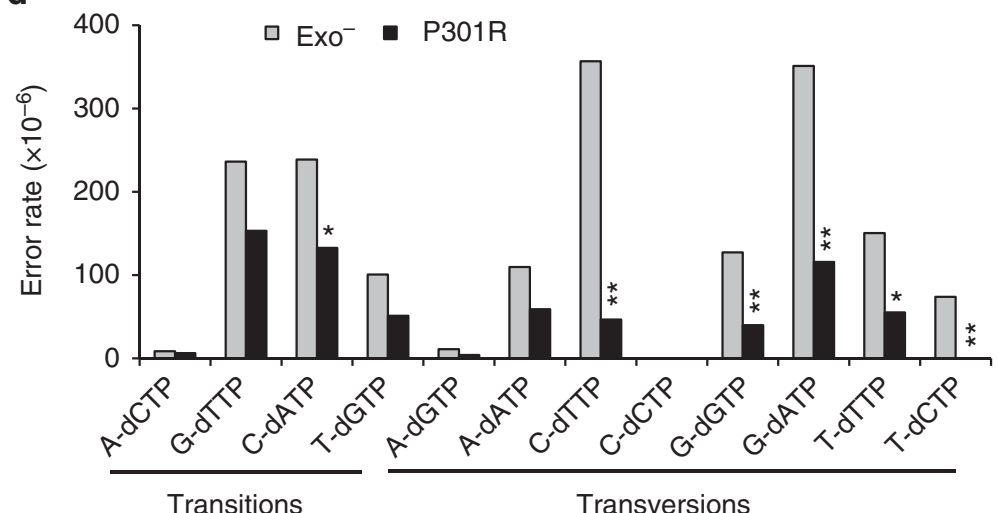

Fig. 1 Pole-P301R retains weak $3^{\prime} \rightarrow 5^{\prime}$ exonuclease activity and is more accurate than the proofreading-deficient Pole. a Exonuclease activity of wild-type Pole (WT), exo- Pole and Pole-P301R was assayed with $25 \mathrm{nM}$ P50/T80 oligonucleotide substrate and $6.25 \mathrm{nM}$ polymerase. Representative of $>10$ independent experiments. $\mathbf{b}$ Exonuclease activity of the Pol $\varepsilon$ variants was assayed with $25 \mathrm{nM}$ P50 single-stranded oligonucleotide and $4 \mathrm{nM}$ polymerase.

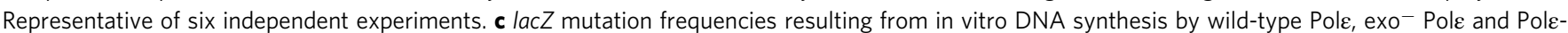
P301R. $\mathbf{d}$ In vitro error rates for the 12 possible base-base mispairs generated by exo-Pole and Pole-P301R. Source data for $\mathbf{a}$ and $\mathbf{b}$ are provided in a Source Data file. Data for $\mathbf{c}$ and $\mathbf{d}$ are from Supplementary Table 1. Asterisks indicate statistically significant differences between exo ${ }^{-}$Pol $\varepsilon$ and Pol $\varepsilon$-P301R: ${ }^{\star} p<$ $0.05 ;{ }^{* *} p<0.01$ (Fisher's exact test)

P301R does not have a particularly high error rate, and all of its observed in vitro infidelity may just result from the partial exonuclease defect.

Ultramutation in vivo results from Pole-P301R errors. Because the modest mutator properties of the purified Pole-P301R (Fig. 1c, d) were inconsistent with its strong mutator effect in vivo ${ }^{11}$, we next asked whether the mutations in the pol2-P301R strains, in fact, resulted from Pole-P301R-mediated DNA synthesis. We previously showed that mutator effects of replicative DNA polymerase variants can be caused by the recruitment of the error-prone translesion synthesis DNA polymerase $\zeta(\mathrm{Pol} \zeta)$ to stalled replication forks ${ }^{19}$. Deletion of the $R E V 3$ gene encoding the catalytic subunit of $\mathrm{Pol} \zeta$ did not decrease the mutation rate in the pol2-P301R strains, indicating that $\mathrm{Pol} \zeta$ is not responsible for the ultramutation (Fig. 2a). We then examined whether errors occurring in the pol2-P301R strains are subject to correction by MMR and, therefore, are generated during replicative DNA synthesis. Tetrad dissection of heterozygous POL2/pol2-P301R $M S H 6 / m s h 6 \Delta$ diploids showed that the combination of the P301R substitution with the MMR defect results in synthetic lethality (Fig. 2b, left). The double mutant pol2-P301R $m s h 6 \Delta$ cells were able to divide and form microcolonies of varying size before cell division stopped (Fig. 2b, right), a phenotype indicative of replication error catastrophe ${ }^{3}$. In contrast, double pol2-4 msh6 mutants carrying exo ${ }^{-}$Pole and lacking the Msh6-dependent MMR were readily produced by sporulation of POL2/pol2-4 $M S H 6 / m s h 6 \Delta$ diploids (Fig. 2b, middle). The synthetic lethality of pol2-P301R and $m s h 6 \Delta$ demonstrates that the pol2-P301R strains accumulate an enormous amount of DNA replication errors, which, in the absence of MMR, exceed the viability threshold. These results also illustrate the much stronger mutator activity of Pole-P301R in vivo, as compared to exo ${ }^{-}$Pole. To gain further insight into the origin of Pole-P301R-mediated mutations, we compared the spectra of base substitutions accumulating in the pol2-4 and pol2-P301R strains to the mutational specificity of the respective polymerases deduced from the in vitro fidelity assays. 
a

\begin{tabular}{lc}
\hline Genotype & Can $^{r}$ mutation rate $\left(\times 10^{-7}\right)$ \\
\hline Wild type & $3.0(2.2-5.6)$ \\
rev3s & $1.2(1.1-1.7)$ \\
pol2-P301R & $230(200-300)$ \\
pol2-P301R rev3s & $300(230-430)$ \\
\hline
\end{tabular}

b

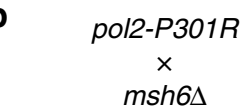

$m s h 6 \Delta$
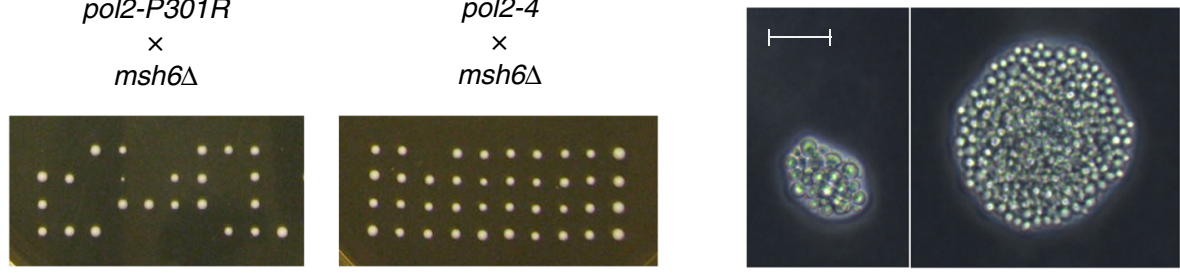

c
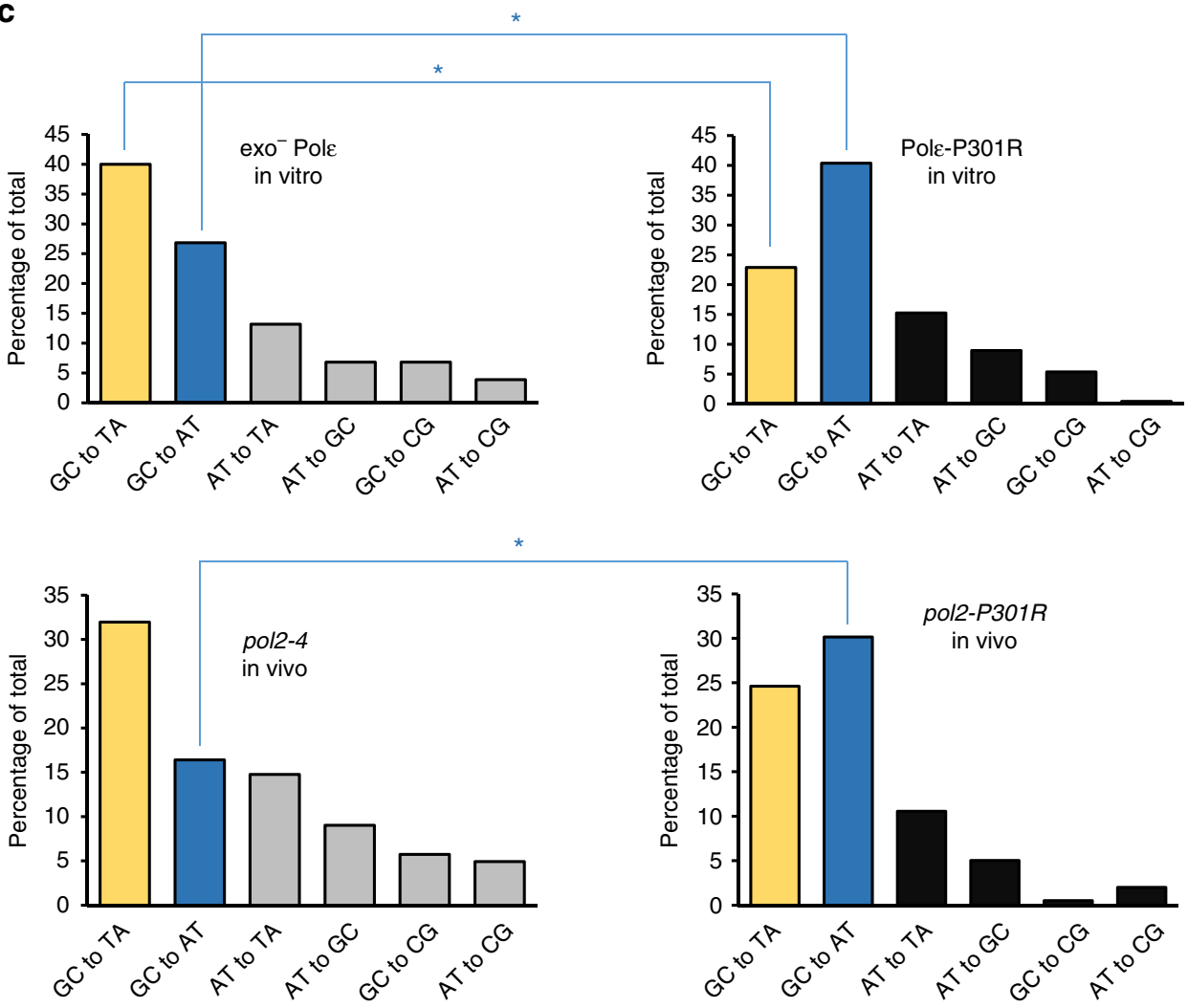

Fig. 2 In vivo evidence suggests that the ultramutator phenotype of pol2-P301R strains results from errors made by Pole-P301R during replicative DNA

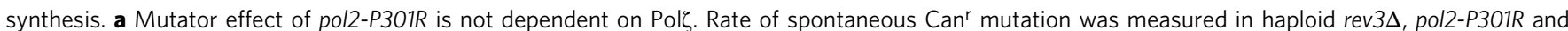
pol2-P301R rev3 $\Delta$ mutants and an isogenic wild-type strain. Mutation rates are given as medians for at least nine cultures with $95 \%$ confidence limits in parentheses. Source data are provided in a Source Data file. $\mathbf{b}$ The pol2-P301R shows synthetic lethal interaction with the MMR defect indicative of a replication error catastrophe. Left, tetrad analysis of diploids heterozygous for pol2-P301R and msh6 , and pol2-4 and msh6 . While double mutants were readily produced by sporulation of $P O L 2 /$ pol2-4 msh6 $/$ MSH6 diploids, no viable pol2-P301R msh6 $\Delta$ spores were obtained from the pol2-P301R $\times$ msh6 cross. Right, two examples of dead cell groups formed upon germination of the pol2-P301R msh6 $\Delta$ haploid spores. Scale bar, $20 \mu \mathrm{m}$. Representative of two independent experiments. c The error signatures of exo- Pole and Pole-P301R are apparent in the in vivo mutational spectra of pol2-4 and pol2-P301R strains, respectively. Proportions of individual base substitutions generated during in vitro synthesis by exo- Pole (top left) and Pole-P301R (top right) were obtained by combining data for the corresponding reciprocal base-base mismatches from Supplementary Table 1. Proportions of individual base substitutions in the pol2-P301R yeast strain (bottom right) were determined by DNA sequence analysis of 194 Can $^{r}$ mutants containing a total of 199 mutations in the CAN1 gene (Supplementary Table 2). The analogous data for the pol2-4 yeast strain (bottom left) are from ${ }^{54}$. Asterisks indicate statistically significant differences in the proportions of GC $\rightarrow$ AT transitions and GC $\rightarrow$ TA transversions $(p<0.01$, Fisher's exact test) 
a 5, Cy5-TGgAACTT TGTACGTCCAAAATTGAAT GACTTGgCCAACTACACTAAGTt

3' ACCT TGAAACAT G CAGGTTTTAACTTACTGAACCGGT TGATGT GATTCAAGGTCCCGAGGACACGAAGCAAAGCAAAAGG
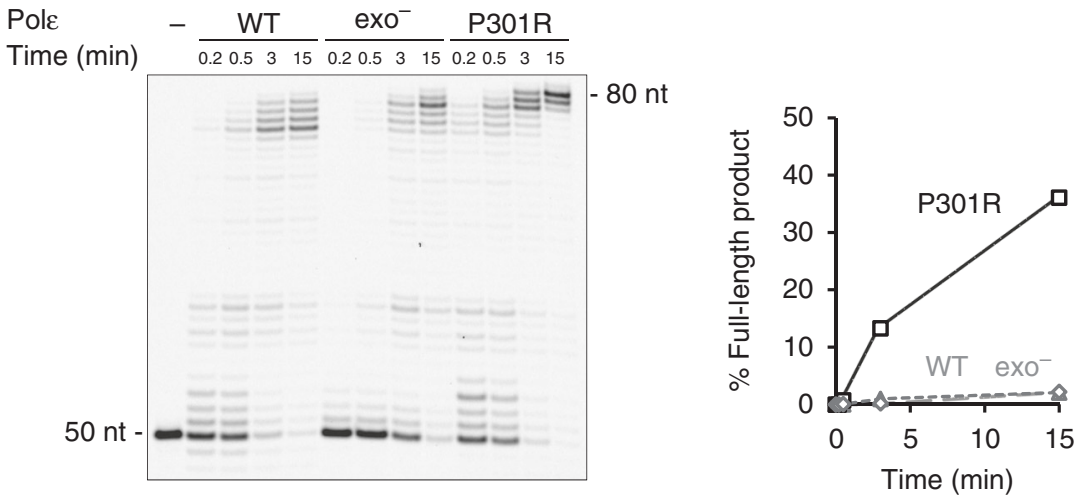

b
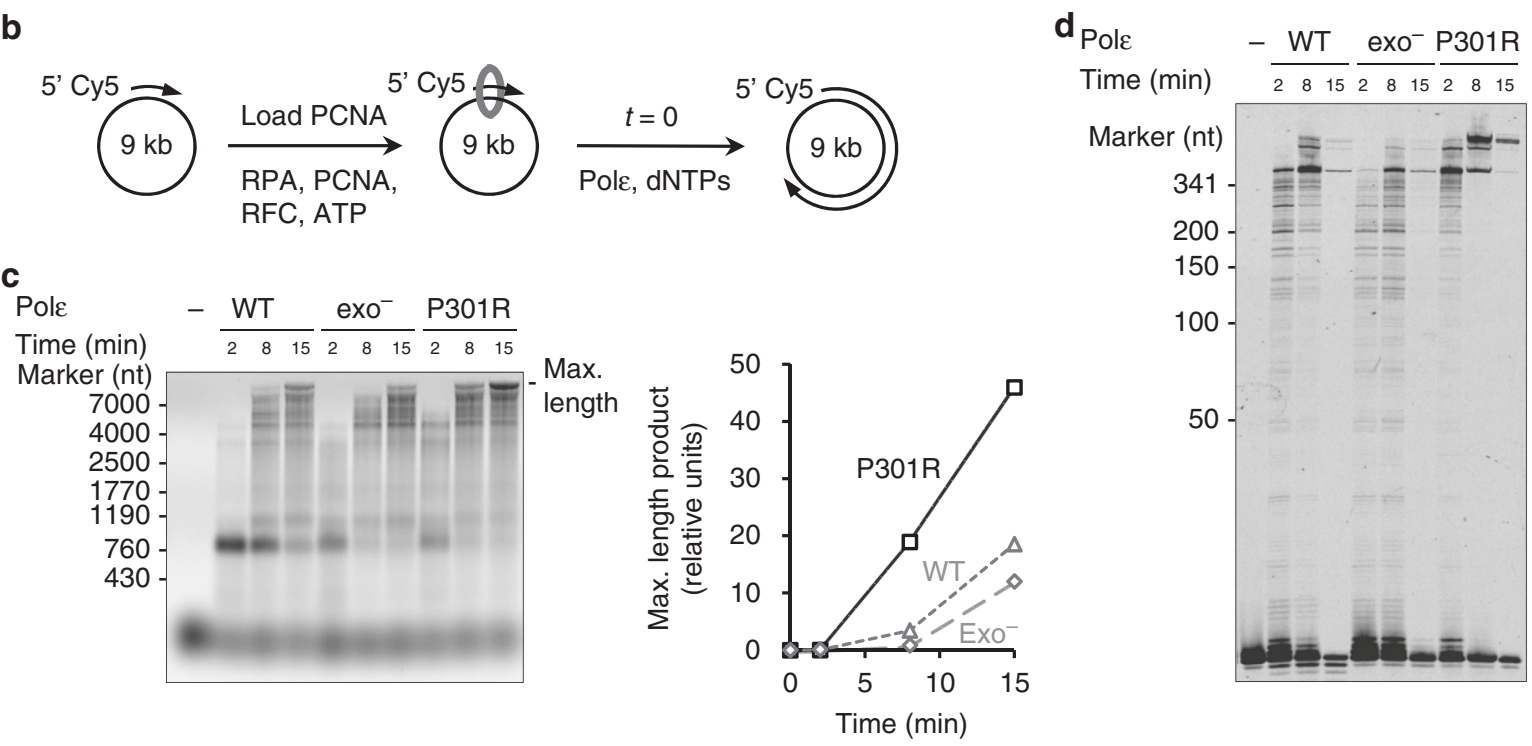

Fig. 3 Pole-P301R has a robust DNA polymerase activity superior to that of the wild-type or proofreading-deficient Pole. a DNA polymerase activity was assayed using $25 \mathrm{nM}$ correctly matched P50/T80a oligonucleotide substrate (shown above the gel image) and $6.25 \mathrm{nM}$ polymerase, and the fraction of full-length product (80 nt) was quantified. Representative of two independent experiments. b Schematic of DNA replication assay on the circular M13/ CAN1(1-1560-F) substrate. c M13/CAN1(1-1560-F) replication reactions were performed at a Pole:substrate ratio of 5:1. The products were separated in a $0.8 \%$ alkaline agarose gel, and the fraction of maximal-length products was quantified. Representative of two independent experiments. $\mathbf{d}$ The M13/CAN1 (1-1560-F) replication reactions were performed at a Pole:substrate ratio of 1:5, and the products were analyzed by 8 M Urea PAGE. One experiment. Source data for $\mathbf{a}, \mathbf{c}$, and $\mathbf{d}$ are provided in a Source Data file

The mutational spectra produced by purified exo- Pole and Pole$\mathrm{P} 301 \mathrm{R}$ in vitro differ primarily in the proportions of the two most frequent classes of base substitutions, GC $\rightarrow$ AT transitions and $\mathrm{GC} \rightarrow \mathrm{TA}$ transversions (Fig. $2 \mathrm{c}$, top left and top right). The in vivo pol2-4 spectrum was remarkably similar to the spectrum of mutations resulting from DNA synthesis by exo ${ }^{-}$Pole in vitro (Fig. 2c, top left and bottom left). At the same time, the in vivo pol2-P301R spectrum showed an increase in the GC $\rightarrow$ AT transition/GC $\rightarrow$ TA transversion ratio predicted by the in vitro specificity of Pole-P301R (Fig. 2c, top right and bottom right). Thus, the exceptionally strong mutator phenotype of the pol2-P301R strains appears to result from replicative DNA synthesis by the PoleP301R variant. The lower error rate of the purified Pole-P301R in comparison to exo ${ }^{-}$Pole (Fig. 1) suggests that additional factors must enhance the impact of its infidelity on mutagenesis in vivo.

Pole-P301R is a hyperactive DNA polymerase. In a search for additional effects of the P301R substitution, we compared the
DNA polymerase activity of wild-type Pole, exo- Pole and PoleP301R. In a primer extension assay using an oligonucleotide template (P50/T80a substrate), Pole-P301R had a substantially higher activity in comparison to both wild-type Pole and exo ${ }^{-}$ Pole, as indicated by a greatly increased accumulation of fulllength products (Fig. 3a). Active site titration indicated that the fraction of active polymerase was comparable in the wild-type Pole, exo ${ }^{-}$Pole and Pole-P301R preparations (Supplementary Fig. 5), therefore, the increased synthesis by Pole-P301R was not due to a higher concentration of active enzyme. We next determined if Pole-P301R also showed an enhanced DNA polymerase activity during copying of long natural templates in reactions reconstituted with the auxiliary replication proteins proliferating cell nuclear antigen (PCNA), replication factor C (RFC) and replication protein A (RPA). PCNA was stably loaded on a singly primed $9.0-\mathrm{kb}$ circular single-stranded DNA substrate, M13/ CAN1(1-1560-F $)^{20}$, and replication reactions were initiated by the addition of Pole (Fig. 3b). Similar to the results with the 


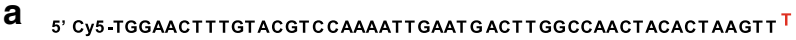

3' ACCT T GAAACAT G CAGGTTTTAAC TTACT GAACCGGT T GATGT GATTCAAGGTCCCGTTTTCACTATGCTATTCTTTTGG
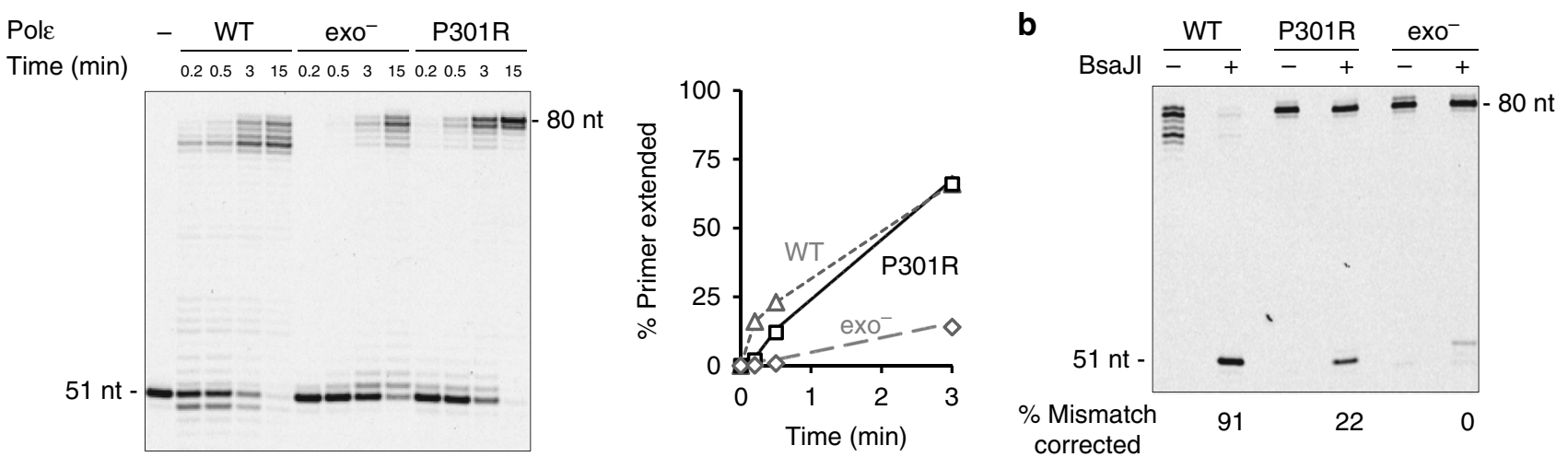

Fig. 4 Increased mismatch extension capacity of Pole-P301R. a DNA polymerase activity was assayed on P51T/T80 oligonucleotide substrate containing a terminal G-T mismatch, and the fraction of primer extended ( $\geq 52 \mathrm{nt}$ ) was quantified. The polymerase and DNA substrate concentrations are as in Fig. 3a. Representative of seven independent experiments. b Pole variants were incubated with the P51T/T80 substrate for 30 min, and relative efficiency of mismatch extension vs. proofreading was determined by Bsall digestion of the reaction products. The appearance of 51-nt restriction fragment indicates that the mismatch has been corrected by the polymerase. The 80-nt fragments resistant to BsaJl digestion represent products of mismatch extension. Representative of two independent experiments. Source data are provided in a Source Data file

oligonucleotide templates, Pole-P301R decidedly outperformed both wild-type Pole and exo- Pole (Fig. 3c, d). The wild-type Pole was slightly more efficient than exo- ${ }^{-}$Pole at accumulating long products in this assay, as was also previously observed with some DNA substrates ${ }^{21,22}$, but Pole-P301R was clearly superior to both of them (Fig. 3c). Separating the reaction products in a sequencing gel showed that DNA synthesis by wild-type Pole and by exo $^{-}$Pole was impeded at several major pause sites, and PoleP301R was much more efficient at bypassing these sites (Fig. 3d).

Increased mismatch extension capacity of Pole-P301R. We next determined whether Pole-P301R had a higher ability to extend mismatched primer termini. Incorrect nucleotide incorporation must be followed by extension of the aberrant primer terminus in order to result in a mutation. Replicative DNA polymerases are generally poor extenders, which is one of the mechanisms contributing to mutation avoidance. The delay in DNA synthesis caused by the inability to extend a mismatched primer terminus normally provides opportunities for correction of the error by intrinsic or extrinsic proofreading mechanisms ${ }^{23}$. In reactions with an oligonucleotide primer-template substrate containing a terminal G-T mismatch, P51T/T80, Pole-P301R showed a greatly increased DNA synthesis activity in comparison to exo- Pole (Fig. 4a). While it was initially delayed relative to the wild-type Pole that can remove the mismatched nucleotide, Pole-P301R was able to catch up and produce the same amount of extended products as the wild-type Pole during the time course of the reaction. It was also more efficient than exo- Pole at extending primers containing internal mismatches in the vicinity of $3^{\prime}$ terminus (Supplementary Fig. 6). Since Pole-P301R has residual exonuclease activity (Fig. 1a), the observed efficient synthesis on the mismatched substrates could potentially result from the action of the exonuclease followed by extension of the resulting correctly matched primer terminus. To be able to distinguish between a true extension of the mismatch and a correction followed by extension, we designed the P51T/T80 substrate such that the T80 template contained a recognition sequence for the BsaJI restriction endonuclease at the primer-template junction. Incorporation of the mismatched 3 -terminal $\mathrm{T}$ of the primer into the reaction product would destroy the restriction site. If the polymerase excised the mismatched $\mathrm{T}$ before extending the primer, the products would be digested by BsaJI. Restriction analysis of full-length extension products showed that PoleP301R excised the mismatched $\mathrm{T}$ in $22 \%$ of cases, while $78 \%$ of products resulted from extension of the abnormal primer terminus (Fig. 4b). In contrast, the wild-type Pole corrected the mismatch in $91 \%$ of cases, and only $9 \%$ of products resulted from direct extension. As expected, no excision occurred in reactions with exo ${ }^{-}$Pole. A faint band at the 52 -nt position likely resulted from slippage of the primer terminus and incorporation of an additional $\mathrm{T}$ across from the upstream A's in the template, followed by extension of the slipped intermediate. Overall, these results indicate that Pole-P301R strongly prefers to extend rather than correct mismatched primer termini, and it greatly surpasses both wild-type Pole and exo- Pole in the extension capacity.

Increased bypass of hairpin DNA structures by Pole-P301R. Unusual DNA secondary structures, such as hairpins, cruciforms, G-quadruplex, triplex, and Z-DNA present obstacles for DNA replication machinery ${ }^{24}$. Inverted repeats capable of forming hairpin structures are particularly common, with many repeats present in every gene. Hairpin extrusion is facilitated by the unwinding of duplex DNA during replication, thus, DNA polymerases often encounter such structures. We previously observed that hairpins with a stem as short as 4-6 nucleotides can significantly impede synthesis by replicative DNA polymerases in vitro ${ }^{20}$. The increased DNA polymerase activity of Pole-P301R on long natural templates could be, in part, due to a more efficient bypass of non-B DNA structures. We compared the efficiency of DNA synthesis by wild-type Pole, exo- Pole, and Pole$\mathrm{P} 301 \mathrm{R}$ on the $\mathrm{P} 50 / \mathrm{T} 80 \mathrm{H}$ substrate containing 6-nt inverted repeats in the template region. The putative hairpin in this substrate would be located 3-nt downstream of the primer terminus. The wild-type Pole was nearly completely blocked by the hairpin and used its exonuclease activity to degrade the primer (Fig. 5a). The exo ${ }^{-}$Pole was significantly inhibited but was able to produce a substantial amount of full-length product at later time points (Fig. 5a). This is consistent with a previous report showing that Pole becomes capable of strand displacement once its exonuclease activity is disrupted ${ }^{21}$. Pole-P301R, however, showed dramatically increased hairpin bypass activity in comparison to exo ${ }^{-}$Pole (Fig. 5a). 

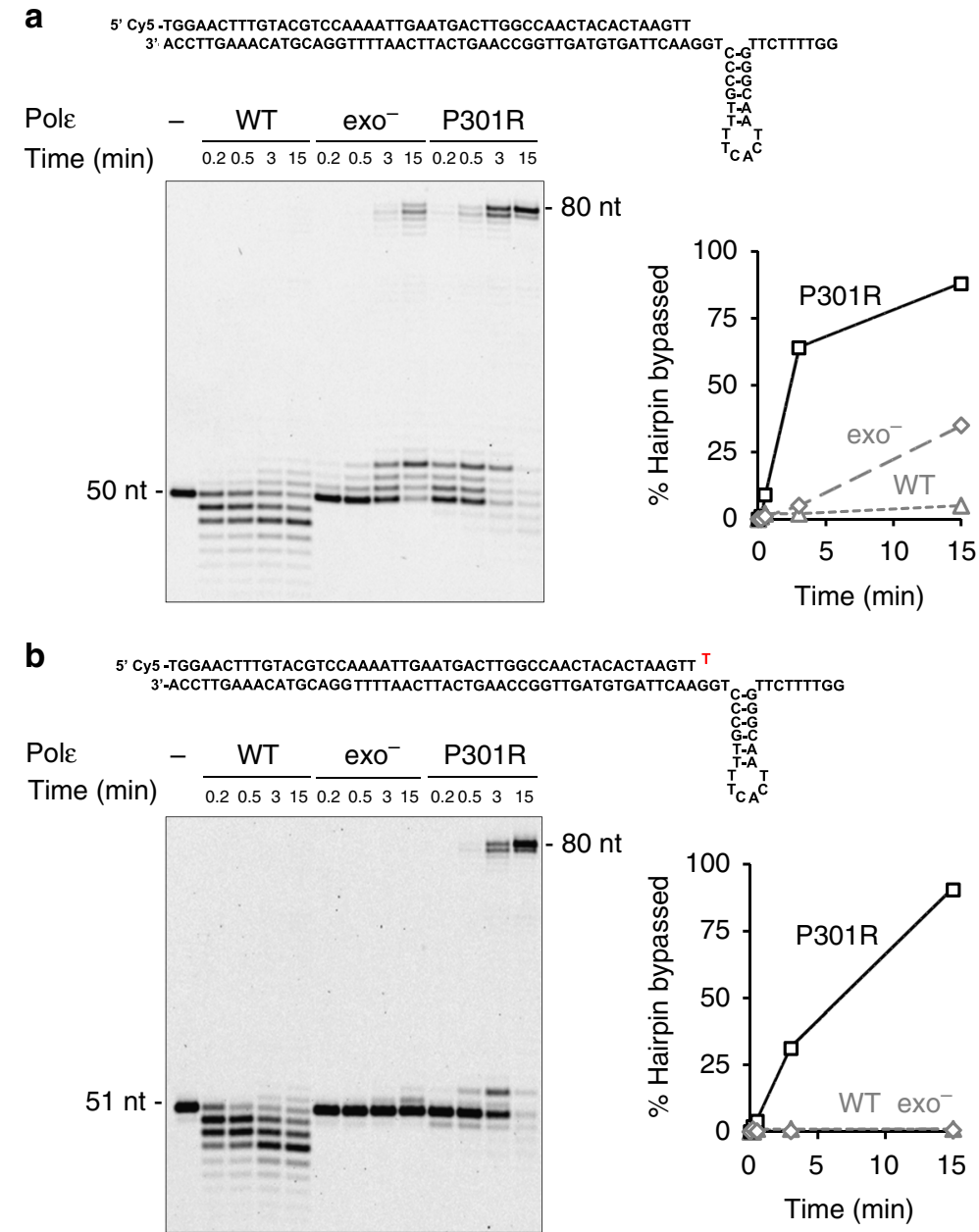

C

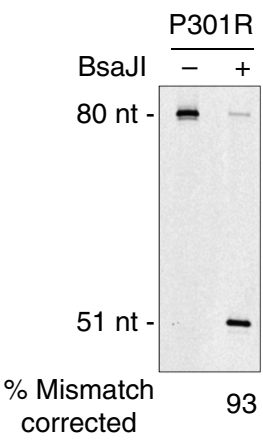

Fig. 5 Increased bypass of hairpin DNA structures by Pole-P301R. The polymerase and DNA substrate concentrations are as in Fig. 3a. a DNA polymerase activity was assayed on $\mathrm{P} 50 / \mathrm{T} 80 \mathrm{H}$ oligonucleotide substrate containing 6-bp inverted repeats in the template region, and the fraction of products longer than $71 \mathrm{nt}$ indicating hairpin bypass was quantified. Representative of three independent experiments. b DNA polymerase activity was assayed on P51T/ $\mathrm{T} 80 \mathrm{H}$ oligonucleotide substrate containing inverted repeats in the template region and a terminal G-T mismatch, and the fraction of products longer than $71 \mathrm{nt}$ indicating hairpin bypass was quantified. Representative of four independent experiments. c Pole-P301R was incubated with the P51T/T80H substrate for $30 \mathrm{~min}$, and relative efficiency of mismatch extension vs. proofreading was determined by Bsall digestion of the reaction products as in Fig. $4 \mathrm{~b}$. One experiment. Source data are provided in a Source Data file

Next, we engineered an even more challenging DNA substrate, $\mathrm{P} 51 \mathrm{~T} / \mathrm{T} 80 \mathrm{H}$, containing the hairpin-forming inverted repeats in the template region and a mismatched primer terminus. Synthesis by both wild-type Pole and exo- Pole was completely blocked by this double obstacle, but Pole-P301R still efficiently produced fulllength products, providing, perhaps, the best illustration of its remarkable power as a DNA polymerase (Fig. $5 b$ ). Quantitative analysis of BsaJI digestion showed that Pole-P301R corrected most of the mismatched primer termini before extending them (Fig. 5c), which could be expected given the impeding effect of the hairpin on polymerization.

\section{Discussion}

The exceptionally strong mutator effect of the human Pole-P286R variant modeled in yeast suggested functional alterations beyond a simple loss of proofreading, but the nature of these additional alterations remained elusive. The high recurrence of Pole-P286R in tumors and the scarcity of mutations that produce catalytically inactive Pole implies that these additional consequences of the arginine substitution may be responsible for its pathogenicity.
The present study shows that, despite the catastrophic rate of replication errors in vivo, purified yeast mimic of Pole-P286R is not remarkably inaccurate. It is more accurate than the exonuclease-deficient Pole and has some proofreading capability. However, a major property that distinguishes the cancerassociated variant from both wild-type and exonucleasedeficient Pol $\varepsilon$ is an abnormally high DNA polymerase activity. Increased activity was observed in all assays used, in the absence and in the presence of accessory proteins, and was particularly impressive with mismatched and secondary structure-containing substrates that generally impede synthesis by replicative DNA polymerases.

A companion study by Parkash et al. ${ }^{14}$ describes the crystal structure of yeast Pole-P301R that may provide a rationale for these unusual properties. In this structure, the side chain of Arg301 dwells in the space that must be occupied by the 3'terminal nucleotide of the primer when Pole is in the editing mode. The arginine substitution also affects metal binding at the exonuclease active site and coordination of the catalytic residue E292. In addition to adverse effects on catalysis, these changes would likely prevent proper positioning of the primer terminus in 

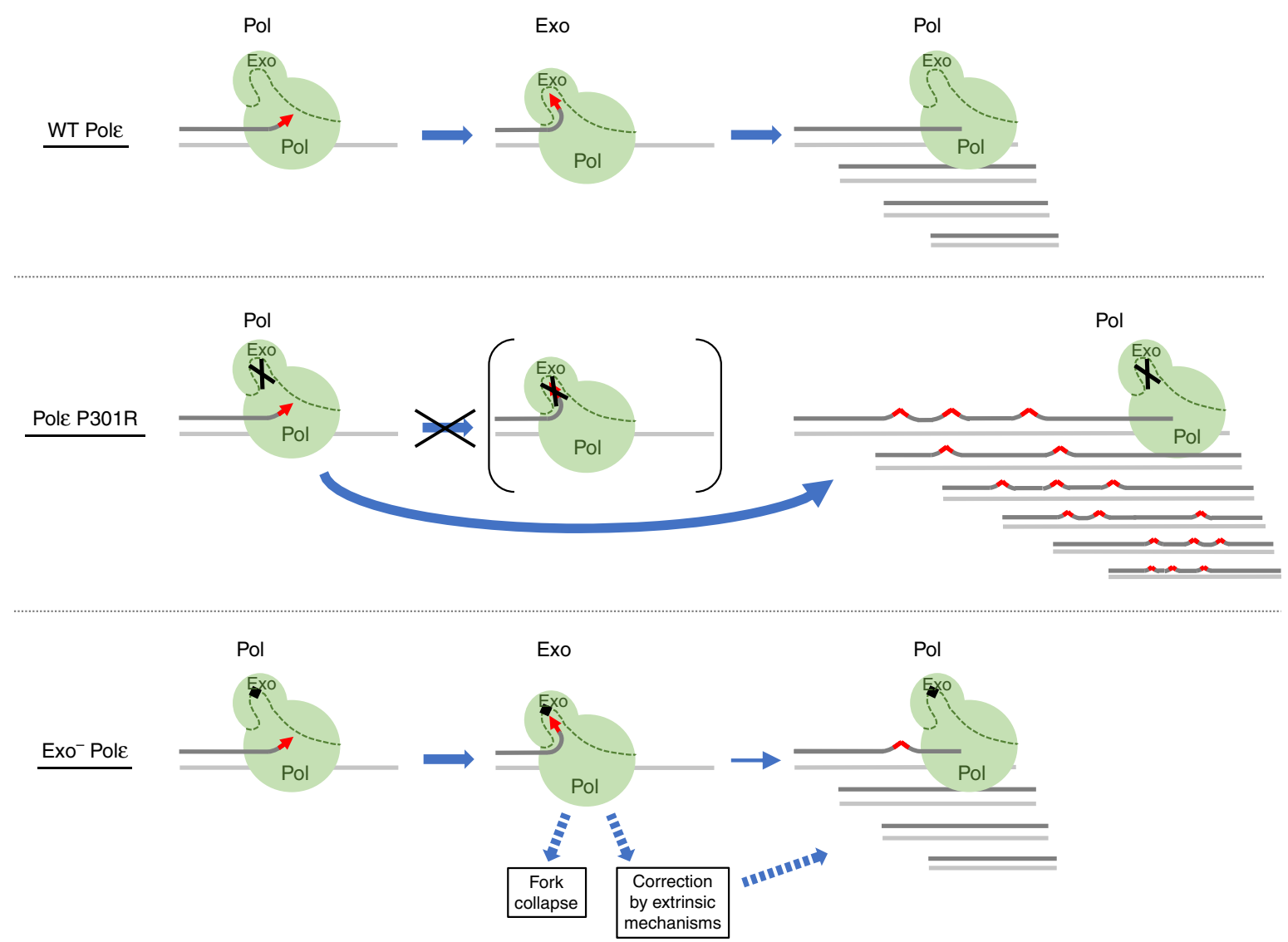

Fig. 6 Pole exonuclease domain alterations as a source of increased DNA polymerase activity and ultramutation in cancers. Synthesis by both wild-type Pole and exo- Pole involves partitioning of the primer terminus between the polymerase (Pol) and exonuclease (Exo) active sites. This partitioning limits the rate of DNA synthesis and prevents efficient mismatch extension, leading to the correction of errors by the intrinsic (wild-type Pole) or extrinsic (exoPole) mechanisms. In contrast, the cancer-associated P301R substitution restricts access of the primer terminus to the exonuclease site, prompting the polymerase to stay in the elongation mode and, thus, resulting in hyperactivity and a high mutation rate

the exonuclease site. In contrast, the catalytic residue mutation in exo $^{-}$Pole prevents hydrolysis but does not create steric hindrance for the movement of the $3^{\prime}$-end to the exonuclease site ${ }^{25}$. This appears to be the key difference between the two enzymes, as no changes were seen in the structure of the DNA polymerase domain. The model in Fig. 6 integrates our findings with the structural data to explain how the local structural alteration in the exonuclease domain could lead to an increased DNA polymerase activity and ultramutator phenotype. Insertion of a noncomplementary nucleotide by the wild-type Pole (Fig. 6, top) inhibits further elongation and promotes transfer of the primer terminus to the exonuclease active site. Removal of the mismatched nucleotide allows Pole to resume DNA synthesis and generate predominantly error-free products. This is consistent with the established role of exonucleolytic proofreading in enhancing the fidelity of replicative DNA polymerases ${ }^{23}$, and, indeed, we observed that the wild-type Pole prefers correction $>10$-fold over extension when presented with a mismatched primer terminus (Fig. 4b). In the case of Pole-P301R (Fig. 6, middle), we propose that the inability to accommodate singlestranded DNA in the exonuclease site forces the enzyme to stay in the polymerization mode, resulting in higher activity, better mismatch extension, and ultimately faster DNA synthesis with the majority of errors converted into mutations. In contrast, exo ${ }^{-}$ Pole (Fig. 6, bottom), while being unable to proofread, still allows partitioning of the DNA between the polymerase and exonuclease sites. This partitioning likely makes exo- Pole slower than PoleP301R and similar to the wild-type Pole in terms of the overall rate of elongation. However, a nucleotide misinsertion would severely impede further synthesis by $\mathrm{exo}^{-}$Pole, prompting it to either remain bound in the editing mode or dissociate. In vitro fidelity assays allow substantial time for extension and multiple binding events, revealing that exo $^{-}$Pole has the potential to generate more mutations than the partially exonuclease-proficient Pole-P301R (Fig. 1c, d). We propose that this potential is not realized in the context of a rapidly moving replication fork in vivo, and the poor mismatch extension ability of exo ${ }^{-}$Pole results in aborted replication products or correction of the mismatch by extrinsic mechanisms (Fig. 6, bottom). This model implies that the ultramutator effect of Pole-P301R results from efficient extension of mismatches formed by canonical nucleotides. In addition, the increased polymerase activity of this Pole variant may facilitate mutagenic bypass of endogenous DNA lesions, a possibility that could be tested in future studies.

While P286R is the most frequently seen variant in tumors, many other recurrent variants affect amino acid residues at the DNA binding interface in the exonuclease domain ${ }^{26}$. When modeled in yeast, the vast majority confer mutator effects exceeding the effects of exonuclease deficiency ${ }^{13}$. It is tempting to suggest that these variants, too, limit the ability of Pole to accommodate DNA in the exonuclease site and result in an increased DNA polymerase activity. At the same time, the rarity of mutations at catalytic residues in the exonuclease domain in cancers could reflect the fact that they do not prevent sliding of the primer terminus to the exonuclease site and, thus, do not provide Pole with the robustness needed to acquire the 
ultramutator phenotype. It is interesting to note that studies of other DNA polymerases, such as Pol $\delta$ and T4 DNA polymerase, have identified amino acid changes in the proofreading domains that impair the ability to switch between polymerase and exonuclease sites, but these mutants do not show increased polymerase activity 27,28 . The unique properties of Pole-P301R suggest that the coordination of polymerase and exonuclease activities is different in Pole, and eliminating the option to bind in the exonuclease mode makes Pole a much more efficient polymerase. While this may be the change selected for during tumorigenesis, it remains to be established how the unusual way of balancing the two catalytic activities facilitates the functions of wild-type Pole in DNA replication and other cellular transactions.

According to the currently accepted eukaryotic replication fork model, Pole is primarily responsible for synthesis of the leading DNA strand, including both polymerization and proofreading of errors, while the second replicative polymerase with a $3^{\prime} \rightarrow 5^{\prime}$ exonuclease activity, Pol $\delta$, synthesizes most of the lagging strand ${ }^{29}$. This view is supported by a multitude of studies, including strand-specific increases in mutagenesis in cells with inaccurate Pole and Pol $\delta$ variants ${ }^{30-33}$, strand-specific ribonucleotide incorporation in cells with Pole and Pol $\delta$ variants deficient in ribonucleotide discrimination ${ }^{34,35}$, a clear role of Pol $\delta$ and not Pole in the proofreading of errors made by Pola ${ }^{36}$ and in Okazaki fragment maturation 37,38 , and the cooperation of Pole and not Pol $\delta$ with the leading strand helicase in reconstituted in vitro replication reactions ${ }^{39}$. It is important to note that all available in vivo evidence for the primary role of Pole as a leading-strand polymerase is based on studies of mutants with altered nucleotide selection or proofreading. In Saccharomyces cerevisiae, the pol2-4 allele encoding $\mathrm{exo}^{-}$Pole and the pol2$M 644 G$ allele affecting nucleotide selectivity have been used to deduce the roles of exonuclease and DNA polymerase activities of Pole $\varepsilon^{32-34}$. The critical assumption in these studies was that the mutant variants correctly reflect the function of wild-type Pole. This assumption relies on the biochemical evidence that the DNA polymerase activity and processivity of the mutant variants is similar to those of the wild-type Pole $\varepsilon^{32,40,41}$. However, the finding that Pole-P301R possessing higher activity causes a two-ordersof-magnitude stronger mutator effect in vivo than $\mathrm{exo}^{-}$Pole or Pole-M644G ${ }^{11}$ suggests that the contribution of Pole to DNA replication can be increased well beyond what these previously studied mutants detected. Our data suggest two possibilities. First, the previously studied variants (exo- Pole, Pole-M644G), and by inference the wild-type Pole, do not replicate the entire leading strand but rather contribute at a small percentage of replication forks or in a small percentage of nucleotide incorporation events. The two-orders-of-magnitude difference in the mutator effects of Pole-P301R and the other variants suggests that this fraction could be as small as $1 \%$. Indeed, Pol $\delta$ can replicate both leading and lagging strands during SV40 origin-dependent replication in vitro ${ }^{42}$. It has also been suggested that Pole contributes little to chromosomal DNA replication in vivo, with Pol $\delta$ primarily synthesizing both strands ${ }^{43}$, but the only attempt to prove this experimentally ${ }^{44}$ has been inconclusive ${ }^{45}$. The second possibility is that Pols might replicate the majority of the leading strand, but, because of its poor mismatch extension capacity, only a tiny proportion of its errors result in mutations. Errors that Pole cannot proofread itself (nearly all errors in the case of exo ${ }^{-} \mathrm{Pol \varepsilon}$ ) would be corrected by extrinsic mechanisms or result in incomplete replication products, as illustrated in Fig. 6. Genetic evidence suggests that the exonuclease activity of Pol $\delta$ can correct errors made by Pol $\varepsilon^{43,46}$, but other cellular nucleases could possibly also help remove a poorly extendable primer terminus. The P301R substitution may be changing this arrangement and greatly increasing the contribution of Pole to DNA replication and/or mutagenesis. Further studies of this and other cancerassociated Pole variants will not only provide insight into the molecular pathogenesis of ultramutated tumors but will also help define the mechanisms that normally regulate the cellular function of Pole.

\section{Methods}

Saccharomyces cerevisiae strains and plasmids. The haploid strain FM113 (MATa ura3-52 trp1-289 leu2-3,112 prb1-1122 prc1-407 pep4-3) ${ }^{47}$ and its pol2-4 and pol2-P301R derivatives were used to overproduce and purify wild-type Pole, exo $^{-}$Pole and Pole-P301R, respectively. Strains used for genetic experiments are isogenic to E134 ${ }^{48}$. The pol2-4 and pol2-P301R mutants of all strains were constructed by replacing the chromosomal POL2 gene with the mutant alleles using plasmids YIpJB1 ${ }^{15}$ and YIpDK1 ${ }^{11}$. DK028/029 and DK007 are pol2-P301R and pol2-4 mutants, respectively, of the haploid strain TM44 (MAT $\alpha$ ade5-1 lys2InsE $E_{A 14}$ trp1-289 his7-2 leu2-3,112 ura3-52 can1 $1::$ loxP $)^{17}$. TM41 (MATa ade5-1 lys2-Tn5-13 trp1-289 his7-2 leu2-3,112 ura3-4 CAN1::Kl.LEU2 msh6 ::KanMX) was constructed by T. M. Mertz in the Shcherbakova laboratory by disrupting the MSH6 gene in TM30 strain ${ }^{17}$ with a PCR-amplified KanMX cassette ${ }^{49}$. TM41 was crossed to DK029 and DK007 to generate diploids (DK517 and DK518, respectively) heterozygous for the pol 2 and msh6 mutations. The haploid strain DK004

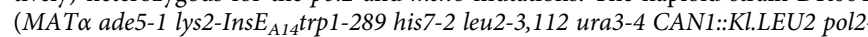
$P 301 R)^{11}$ was used for the mutational spectra analysis. The haploid strains CB29 and CB30 are pol2-P301R mutants of OK29 (MAT $\alpha$ ade5-1 lys2::InsE $E_{A 14}$ trp1-289 his7-2 leu2-3,112 ura3-G764A-LEU2) and its rev3 $\triangle:: K a n M X$ variant $^{50}$, respectively. OK29, OK29 rev3 $\Delta:: K a n M X, \mathrm{CB} 29$ and CB30 were used to study the genetic interaction of the pol2-P301R and rev3 mutations.

Plasmids pJL1 and pJL6 for overproduction of the four subunits of yeast Pole $\varepsilon^{51}$ were kindly provided by Erik Johansson (Umeå University, Sweden). The pol2-4 and pol2-P301R mutations were introduced into the POL2 gene in pJL1 by sitedirected mutagenesis.

Proteins. Untagged wild-type Pole, exo ${ }^{-}$Pole, and Pole-P301R were purified by conventional chromatography from yeast strains overproducing all four Pole subunits using an adaptation of the previously described procedure ${ }^{51}$. The purification buffers were as follows: buffer A contained $150 \mathrm{mM}$ Tris-acetate, $\mathrm{pH} 7.8$, $50 \mathrm{mM}$ sodium acetate, $2 \mathrm{mM}$ EDTA, $1 \mathrm{mM}$ EGTA, $10 \mathrm{mM} \mathrm{NaHSO} 3,1 \mathrm{mM}$ dithiothreitol, $5 \mu \mathrm{M}$ pepstatin A, $5 \mu \mathrm{M}$ leupeptin, $0.3 \mathrm{mM}$ phenylmethylsulfonyl fluoride, and $5 \mathrm{mM}$ benzamidine; buffer B contained $25 \mathrm{mM}$ Hepes- $\mathrm{NaOH}, \mathrm{pH}$ 7.6, $10 \%$ glycerol, $1 \mathrm{mM}$ EDTA, $0.5 \mathrm{mM}$ EGTA, 0.005\% Nonidet P-40, $1 \mathrm{mM}$ dithiothreitol, $5 \mu \mathrm{M}$ pepstatin $\mathrm{A}, 5 \mu \mathrm{M}$ leupeptin, $5 \mathrm{mM} \mathrm{NaHSO}_{3}$, and sodium acetate at a concentration (mM) indicated by the subscript number (for example, buffer $B_{50}$ is buffer B with $50 \mathrm{mM}$ sodium acetate); and buffer $\mathrm{C}$ contained $25 \mathrm{mM}$ Hepes$\mathrm{NaOH}, \mathrm{pH} 7.6,10 \%$ glycerol, 1 mM EDTA, 0.005\% Nonidet P-40, 400 mM sodium acetate, $5 \mathrm{mM}$ dithiothreitol, $5 \mathrm{mM} \mathrm{NaHSO}, 2 \mu \mathrm{M}$ leupeptin, and $2 \mu \mathrm{M}$ pepstatin A. Approximately $100 \mathrm{~g}$ of wet cells were harvested from $20 \mathrm{~L}$ of culture medium

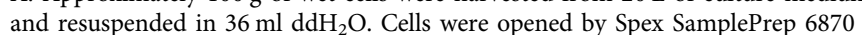
Freezer/Mill (SPEX SamplePrep, USA). The volume of cell extract was measured, and $5 \times$ buffer $A$ stock and ammonium sulfate were added to final concentrations of $1 \times$ buffer A and $175 \mathrm{mM}$ ammonium sulfate. $0.4 \mathrm{ml}$ of $10 \%$ PEI, pH 7.9 was then added dropwise per $10 \mathrm{~mL}$ of cell extract, and the extract was stirred on the ice for $15 \mathrm{~min}$, followed by centrifugation at $39,000 \times \mathrm{g}$ for $30 \mathrm{~min}$ at $4{ }^{\circ} \mathrm{C}$. Next, $2.8 \mathrm{~g}$ of solid ammonium sulfate was added per $10 \mathrm{~mL}$ of supernatant, dissolved by stirring on ice for $45 \mathrm{~min}$, and proteins were precipitated by centrifugation at $39,000 \times \mathrm{g}$ for $30 \mathrm{~min}$ at $4{ }^{\circ} \mathrm{C}$. The precipitate was resuspended in $50 \mathrm{~mL}$ of buffer $\mathrm{B}_{50}$, and $1.06 \mathrm{~g}$ of solid ammonium sulfate was added per $10 \mathrm{~mL}$ of sample, followed by stirring on ice for $45 \mathrm{~min}$ and centrifugation at $39,000 \times \mathrm{g}$ for $30 \mathrm{~min}$ at $4{ }^{\circ} \mathrm{C}$. Then, $0.55 \mathrm{~g}$ of solid ammonium sulfate was added per $10 \mathrm{~mL}$ of supernatant, followed by stirring on ice for $45 \mathrm{~min}$ and centrifugation at $39,000 \times \mathrm{g}$ for $30 \mathrm{~min}$ at $4^{\circ} \mathrm{C}$. The Poleenriched precipitate was resuspended in $50 \mathrm{~mL}$ of buffer $B_{50}$ and frozen. The following day, the sample was dialyzed against $2 \mathrm{~L}$ of buffer $\mathrm{B}_{50}$ for $2 \mathrm{~h}$ and centrifuged at $39,000 \times g$ for $30 \mathrm{~min}$ at $4{ }^{\circ} \mathrm{C}$. The supernatant was loaded onto a $20-\mathrm{mL}$ SP column (GE, USA) equilibrated with $B_{200}$, the column was washed with $B_{200}$, and proteins were eluted with $B_{750}$. The SP fractions were loaded onto a $5-\mathrm{mL}$ HiTrap Q column (GE, USA) equilibrated with $B_{500}$, the column was washed with $B_{200}$, and proteins were eluted with a $40-\mathrm{mL}$ linear gradient from $B_{200}$ to $B_{1200}$. The HiTrap Q fractions were diluted with buffer $B_{0}$ to a final sodium acetate concentration of $100 \mathrm{mM}$. The samples were loaded onto a Mono S column (GE, USA) equilibrated with $B_{100}$, and proteins were eluted with a $20-\mathrm{mL}$ linear gradient from $B_{100}$ to $B_{1200}$. The Mono $S$ fractions were concentrated to a final volume of $200 \mu \mathrm{L}$ by spinning in Amicon Ultra- $0.5 \mathrm{~mL} 3 \mathrm{~K}$ Centrifugal Filters (Millipore, USA) in $40^{\circ}$ fixed angle rotor at $19,000 \times g$ at $4^{\circ} \mathrm{C}$ and loaded onto Superdex $20010 / 300 \mathrm{GL}$ filtration column (GE, USA) equilibrated with buffer C. The gel filtration fractions were aliquoted and stored at $-80^{\circ} \mathrm{C}$.

The preparation of yeast PCNA used in this work has been described ${ }^{17}$. To purify yeast RPA, E. coli strain BL21(DE3) was transformed by the expression vector p11d-tRPA ${ }^{52}$, grown to $\mathrm{OD}_{600}$ of 0.6 at $37^{\circ} \mathrm{C}$, and induced by $0.4 \mathrm{mM}$ IPTG for $2 \mathrm{~h}$. RPA was then purified using a $10-\mathrm{mL}$ Affi-Gel Blue column (Bio-Rad), a 
HAP column (Bio-Rad), and a Mono-Q(HR5/5) column (GE). Yeast RFC was kindly provided by Peter Burgers (Washington University School of Medicine).

Exonuclease and polymerase assays on oligonucleotides. Substrates for DNA polymerase and exonuclease assays were prepared by annealing Cy5-labeled oligonucleotides P50 (Cy5-5'-TGGAACTTTGTACGTCCAAAATTGAATGACTTG GCCAACTACACTAAGTT-3) or P51T (Cy5-5'-TGGAACTTTGTACGTCCAAA ATTGAATGACTTGGCCAACTACACTAAGTTT-3) to 80-mer templates T80a (5'-GGAAAACGAAACGAAGCACAGGAGCCCTGGAACTTAGTGTAGTTGG CCAAGTCATTCAATTTTGGACGTACAA $\overline{A G T T C C A}$-3) or T80 (5'-GGTTTT CTTATCGTATCACTTTTGCCCTGGAACTTAGTGTAGTTGGCCAAGTCATT CAATTTTGGACGTACAAAGTTCCA -3 ) containing a BsaJI restriction site sequence (underlined), or T80H (5'-GGTTTTCTTGGGCAATCACTTTTG CCCTGGAACTTAGTGTAGTTGGCCAAGTCATTCAATTTTGGACGTA CAAAGTTCCA-3) containing the BsaJI recognition sequence and 6-nt inverted repeats (highlighted in bold). The annealing was performed by incubating the primer and template at a ratio of $1: 1$ in the presence of $150 \mathrm{mM} \mathrm{NaAc}$ at $92^{\circ} \mathrm{C}$ for $2 \mathrm{~min}$ and then cooling slowly to room temperature $(\sim 2 \mathrm{~h})$. Exonuclease activity was also analyzed using the single-stranded P50 oligonucleotide alone. For exonuclease assays, the $10-\mu \mathrm{L}$ reaction contained $40 \mathrm{mM}$ Tris- $\mathrm{HCl} \mathrm{pH} \mathrm{7.8,1} \mathrm{mM}$ dithiothreitol, $0.2 \mathrm{mg} \mathrm{mL}^{-1}$ bovine serum albumin, $8 \mathrm{mM} \mathrm{MgAc} 2,125 \mathrm{mM} \mathrm{NaAc}$, $25 \mathrm{nM}$ oligonucleotide substrate, and Pole at the indicated concentration. For DNA polymerase assays, the reactions additionally contained dNTPs at their intracellular S-phase concentrations $(30 \mu \mathrm{M} \mathrm{dCTP}, 80 \mu \mathrm{M}$ dTTP, $38 \mu \mathrm{M}$ dATP, and $26 \mu \mathrm{M}$ dGTP $)^{17}$. The samples were incubated at $30{ }^{\circ} \mathrm{C}$ for the times indicated. For BsaJI restriction digestion, the samples were desalted by centrifugation through $\mathrm{G} 50$ microspin columns (GE Healthcare) and incubated with BsaJI at $60^{\circ} \mathrm{C}$ for $1 \mathrm{~h}$. The reactions were quenched by the addition of an equal volume of $2 \times$ loading buffer containing $95 \%$ deionized formamide, $100 \mathrm{mM}$ EDTA, and $0.025 \%$ Orange G. After boiling for $3 \mathrm{~min}$ and cooling on ice, $6-\mu \mathrm{L}$ samples were subjected to electrophoresis in $10 \%$ denaturing polyacrylamide gel containing $8 \mathrm{M}$ urea in $1 \times \mathrm{TBE}$. Quantification was done by fluorescence imaging on a Typhoon system (GE Healthcare).

Replication assays on M13/CAN1(1-1560-F) substrate. Singly primed circular DNA substrates for DNA polymerase assays were prepared by annealing the Cy5labeled oligonucleotide P50-M13 (Cy5-5'-AAGGAATCTTTGTGAGAAAACTGT GAAAGAGGATGTAACAGGGATGAATG-3) to the M13/CAN1(1-1560-F) single-stranded $\mathrm{DNA}^{20}$ as described above. For analysis by alkaline agarose gel electrophoresis, $10-\mu \mathrm{L}$ replication reactions contained $40 \mathrm{mM}$ Tris- $\mathrm{HCl} \mathrm{pH} 7.8$, $8 \mathrm{mM} \mathrm{MgAc}, 125 \mathrm{mM}$ NaAc, $1 \mathrm{mM}$ dithiothreitol, $0.2 \mathrm{mg} \mathrm{mL}^{-1}$ bovine serum albumin, $1 \mathrm{mM}$ ATP, dNTPs at the intracellular S-phase concentrations (see previous subsection), $20 \mathrm{nM}$ singly primed M13/CAN1(1-1560-F), 7.5 $\mu \mathrm{M}$ RPA, $2 \mathrm{nM}$ RFC, $20 \mathrm{nM}$ PCNA, and $100 \mathrm{nM}$ wild-type Pole, exo- Pole or Pole-P301R. For analysis in sequencing gel, $30-\mu \mathrm{L}$ reactions contained $40 \mathrm{mM}$ Tris- $\mathrm{HCl} \mathrm{pH} \mathrm{7.8,}$ $8 \mathrm{mM} \mathrm{MgAc}_{2}, 125 \mathrm{mM}$ NaAc, $1 \mathrm{mM}$ dithiothreitol, $0.2 \mathrm{mg} \mathrm{mL}^{-1}$ bovine serum albumin, $1 \mathrm{mM}$ ATP, dNTPs at the intracellular S-phase concentrations, $20 \mathrm{nM}$ singly primed M13/CAN1(1-1560-F), 7.5 $\mu$ M RPA, 2 nM RFC, $20 \mathrm{nM}$ PCNA, and

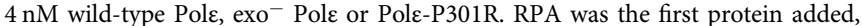
followed by a 1-min incubation at $30^{\circ} \mathrm{C}$, then RFC and PCNA were added followed by another 1 -min incubation at $30^{\circ} \mathrm{C}$, and then the replication was initiated by the addition of Pole. Reactions were stopped by the addition of $1 \mu \mathrm{L}$ of $500 \mathrm{mM}$ EDTA and $1 \mu \mathrm{L}$ of $2 \%$ sodium dodecyl sulfate (SDS), incubated with $2 \mu \mathrm{L}$ of $20 \mathrm{mg} \mathrm{mL}^{-1}$ Proteinase $\mathrm{K}$ (ThermoFisher Scientific) at $55^{\circ} \mathrm{C}$ for $1 \mathrm{~h}$ and purified by phenol/ chloroform extraction. For alkaline agarose gel electrophoresis, $10-\mu \mathrm{L}$ samples were mixed with $2 \mu \mathrm{L}$ of $6 \times$ alkaline loading buffer containing $300 \mathrm{mM} \mathrm{NaOH}, 6 \mathrm{mM}$ EDTA, 18\% (w/v) Ficoll, 0.15\% (w/v) bromocresol green, and 0.25\% (w/v) xylene cyanol, and the reaction products were separated in $0.8 \%$ alkaline agarose gel. For sequencing gels, DNA from $30-\mu \mathrm{L}$ samples was precipitated by ethanol and dissolved in $6 \mu \mathrm{L}$ of $2 \times$ loading buffer containing $95 \%$ deionized formamide, $25 \mathrm{mM}$ EDTA, and $0.025 \%$ Orange G. After boiling for $3 \mathrm{~min}$ and cooling on ice, the samples were subjected to electrophoresis in $10 \%$ denaturing polyacrylamide gel containing $8 \mathrm{M}$ urea in $1 \times$ TBE. Quantification was done by fluorescence imaging on a Typhoon system (GE Healthcare).

In vitro DNA synthesis fidelity. Double-stranded M13mp2 substrate with a 407nucleotide single-stranded region was prepared by annealing single-stranded M13mp2 DNA to 6.8-kb PvuII fragment of double-stranded M13mp2 DNA ${ }^{16,17}$ and gel-purified. DNA synthesis reactions $(25 \mu \mathrm{L})$ contained $40 \mathrm{mM}$ Tris- $\mathrm{HCl}(\mathrm{pH}$ 7.8), $8 \mathrm{mM} \mathrm{MgAc}, 125 \mathrm{mM} \mathrm{NaAc}, 1 \mathrm{mM}$ dithiothreitol, $0.2 \mathrm{mg} \mathrm{mL}^{-1}$ bovine serum albumin, $0.5 \mathrm{mM}$ ATP, dNTPs at the intracellular S-phase concentrations, 1 nM gapped substrate, $200 \mathrm{nM}$ RPA, $8 \mathrm{nM}$ RFC, $20 \mathrm{nM}$ PCNA, and $6.25 \mathrm{nM}$ wildtype Pole, exo- Pole or Pole-P301R. The order of protein addition was the same as in M13/CAN1(1-1560-F) replication assays. The reactions were incubated at $30^{\circ} \mathrm{C}$ for $10 \mathrm{~min}$ or $15 \mathrm{~min}$ and stopped by placing the tubes on ice and adding $1.5 \mu \mathrm{L}$ of $0.5 \mathrm{M}$ EDTA. The efficiency of gap filling was monitored by agarose gel electrophoresis. Transformation of $E$. coli with the reaction products, scoring of mutant plaques, single-stranded DNA isolation from purified plaques, DNA sequencing and error rate calculation were as previously described ${ }^{16,41}$. All data are based on analysis of lacZ mutants from at least two independent gap-filling reactions.
In vivo mutation rate and spectrum. The rate of spontaneous $\mathrm{Can}^{\mathrm{r}}$ mutation was measured by fluctuation analysis using at least two independently constructed strains of each genotype. Nine to eighteen $7-\mathrm{mL}$ cultures were started for each strain from single colonies and grown to the stationary phase in liquid yeast extract peptone dextrose medium supplemented with $60 \mathrm{mg} / \mathrm{L}$ adenine and $60 \mathrm{mg} / \mathrm{L}$ uraci (YPDAU). Cells were plated after appropriate dilutions onto synthetic complete medium containing L-canavanine $(60 \mathrm{mg} / \mathrm{L})$ and lacking arginine (SC + CAN) for $\mathrm{Can}^{\mathrm{r}}$ mutant count and onto synthetic complete (SC) medium for viable count. $\mathrm{Can}^{\mathrm{r}}$ mutant frequency was calculated by dividing the $\mathrm{Can}^{\mathrm{r}}$ mutant count by the viable cell count. Mutation rate was calculated from mutant frequency by using the Drake equation ${ }^{53}$. The significance of differences in the mutation rate was assessed by using Wilcoxon-Mann-Whitney non-parametric test. For the mutational spectra determination, independent colonies of the pol2-P301R strain were streaked on YPDAU plates, grown for two days at $30^{\circ}$, and replica-plated onto SC + CAN medium to select for can 1 mutants. One Can ${ }^{\mathrm{r}}$ colony was picked from each patch, and the CAN1 gene was amplified by PCR and Sanger-sequenced.

\section{Data availability}

All data used to reach the conclusions are presented fully within the Article and the Supplementary material, and available from the corresponding author upon reasonable request. A Reporting Summary is available as a Supplementary Information file. The source data underlying Figs. 1a, b, 2a, 3a, c, d, 4a, b, 5a-c and Supplementary Figs. 1, 2b, c, 3, 5a, b and 6a-f are provided as a Source Data file.

Received: 19 April 2018 Accepted: 12 December 2018

Published online: 22 January 2019

\section{References}

1. Ganai, R. A. \& Johansson, E. DNA replication-A matter of fidelity. Mol. Cell 62, 745-755 (2016)

2. Kunkel, T. A. DNA replication fidelity. J. Biol. Chem. 279, 16895-16898 (2004).

3. Morrison, A., Johnson, A. L., Johnston, L. H. \& Sugino, A. Pathway correcting DNA replication errors in Saccharomyces cerevisiae. EMBO J. 12, 1467-1473 (1993).

4. Barbari, S. R. \& Shcherbakova, P. V. Replicative DNA polymerase defects in human cancers: consequences, mechanisms, and implications for therapy. DNA Repair 56, 16-25 (2017).

5. Campbell, B. B. et al. Comprehensive analysis of hypermutation in human cancer. Cell 171, 1042-1056 (2017).

6. Cerami, E. et al. The cBio cancer genomics portal: an open platform for exploring multidimensional cancer genomics data. Cancer Discov. 2, 401-404 (2012)

7. Forbes, S. A. et al. COSMIC: exploring the world's knowledge of somatic mutations in human cancer. Nucleic Acids Res. 43, D805-D811 (2015)

8. Grossman, R. L. et al. Toward a shared vision for cancer genomic data. $N$. Engl. J. Med 375, 1109-1112 (2016).

9. Palles, C. et al. Germline mutations affecting the proofreading domains of POLE and POLD1 predispose to colorectal adenomas and carcinomas. Nat. Genet. 45, 136-144 (2013)

10. Shinbrot, E. et al. Exonuclease mutations in DNA polymerase epsilon reveal replication strand specific mutation patterns and human origins of replication. Genome Res. 24, 1740-1750 (2014).

11. Kane, D. P. \& Shcherbakova, P. V. A common cancer-associated DNA polymerase $\varepsilon$ mutation causes an exceptionally strong mutator phenotype, indicating fidelity defects distinct from loss of proofreading. Cancer Res. 74, 1895-1901 (2014)

12. Li, H. D. et al. Polymerase-mediated ultramutagenesis in mice produces diverse cancers with high mutational load. J. Clin. Invest. 128, 4179-4191 (2018).

13. Barbari, S. R., Kane, D. P., Moore, E. A. \& Shcherbakova, P. V. Functional analysis of cancer-associated DNA polymerase $\varepsilon$ variants in Saccharomyces cerevisiae. G3 8, 1019-1029 (2018).

14. Parkash, V. et al. Structural consequence of the most frequently recurring cancer-associated substitution in DNA polymerase $\varepsilon$. Nat. Commun. https:// doi.org/10.1038/s41467-018-08114-9 (2018).

15. Morrison, A., Bell, J. B., Kunkel, T. A. \& Sugino, A. Eukaryotic DNA polymerase amino acid sequence required for $3^{\prime}-5^{\prime}$ exonuclease activity. Proc. Natl Acad. Sci. USA 88, 9473-9477 (1991).

16. Bebenek, K. \& Kunkel, T. A. Analyzing fidelity of DNA polymerases. Methods Enzymol. 262, 217-232 (1995)

17. Mertz, T. M., Sharma, S., Chabes, A. \& Shcherbakova, P. V. Colon cancerassociated mutator DNA polymerase $\delta$ variant causes expansion of dNTP pools increasing its own infidelity. Proc. Natl Acad. Sci. USA 112, E2467-E2476 (2015).

18. Williams, L. N. et al. dNTP pool levels modulate mutator phenotypes of errorprone DNA polymerase $\varepsilon$ variants. Proc. Natl Acad. Sci. USA 112, E2457-E2466 (2015). 
19. Northam, M. R., Garg, P., Baitin, D. M., Burgers, P. M. \& Shcherbakova, P. V. A novel function of DNA polymerase $\zeta$ regulated by PCNA. EMBO J. 25, 4316-4325 (2006).

20. Northam, M. R. et al. DNA polymerases $\zeta$ and Rev1 mediate error-prone bypass of non-B DNA structures. Nucleic Acids Res. 42, 290-306 (2014).

21. Ganai, R. A., Zhang, X. P., Heyer, W. D. \& Johansson, E. Strand displacement synthesis by yeast DNA polymerase $\varepsilon$. Nucleic Acids Res. 44, 8229-8240 (2016).

22. Sabouri, N. \& Johansson, E. Translesion synthesis of abasic sites by yeast DNA polymerase $\varepsilon$. J. Biol. Chem. 284, 31555-31563 (2009).

23. Reha-Krantz, L. J. DNA polymerase proofreading: multiple roles maintain genome stability. Biochim Biophys. Acta 1804, 1049-1063 (2010).

24. Mirkin, E. V. \& Mirkin, S. M. Replication fork stalling at natural impediments. Microbiol Mol. Biol. Rev. 71, 13-35 (2007).

25. Hogg, M. et al. Structural basis for processive DNA synthesis by yeast DNA polymerase ع. Nat. Struct. Mol. Biol. 21, 49-55 (2014).

26. Rayner, E. et al. A panoply of errors: polymerase proofreading domain mutations in cancer. Nat. Rev. Cancer 16, 71-81 (2016).

27. Jin, Y. H. et al. The multiple biological roles of the 3 '--> 5' exonuclease of Saccharomyces cerevisiae DNA polymerase $\delta$ require switching between the polymerase and exonuclease domains. Mol. Cell Biol. 25, 461-471 (2005)

28. Stocki, S. A., Nonay, R. L. \& Reha-Krantz, L. J. Dynamics of bacteriophage T4 DNA polymerase function: identification of amino acid residues that affect switching between polymerase and 3'-->5' exonuclease activities. J. Mol. Biol. 254, 15-28 (1995).

29. Burgers, P. M. \& Kunkel, T. A. Eukaryotic DNA replication fork. Annu Rev. Biochem 86, 417-438 (2017).

30. Larrea, A. A. et al. Genome-wide model for the normal eukaryotic DNA replication fork. Proc. Natl Acad. Sci. USA 107, 17674-17679 (2010).

31. Nick McElhinny, S. A., Gordenin, D. A., Stith, C. M., Burgers, P. M. \& Kunkel, T. A. Division of labor at the eukaryotic replication fork. Mol. Cell 30, 137-144 (2008).

32. Pursell, Z. F., Isoz, I., Lundstrom, E. B., Johansson, E. \& Kunkel, T. A. Yeast DNA polymerase $\varepsilon$ participates in leading-strand DNA replication. Science 317, 127-130 (2007).

33. Shcherbakova, P. V. \& Pavlov, Y. I. 3'-->5' exonucleases of DNA polymerases $\varepsilon$ and $\delta$ correct base analog induced DNA replication errors on opposite DNA strands in Saccharomyces cerevisiae. Genetics 142, 717-726 (1996).

34. Clausen, A. R. et al. Tracking replication enzymology in vivo by genome-wide mapping of ribonucleotide incorporation. Nat. Struct. Mol. Biol. 22, 185-191 (2015).

35. Daigaku, Y. et al. A global profile of replicative polymerase usage. Nat. Struct. Mol. Biol. 22, 192-198 (2015).

36. Pavlov, Y. I. et al. Evidence that errors made by DNA polymerase $a$ are corrected by DNA polymerase $\delta$. Curr. Biol. 16, 202-207 (2006).

37. Garg, P., Stith, C. M., Sabouri, N., Johansson, E. \& Burgers, P. M. Idling by DNA polymerase $\delta$ maintains a ligatable nick during lagging-strand DNA replication. Genes Dev. 18, 2764-2773 (2004).

38. Jin, Y. H. et al. The 3'-->5' exonuclease of DNA polymerase $\delta$ can substitute for the 5 ' flap endonuclease Rad27/Fen1 in processing Okazaki fragments and preventing genome instability. Proc. Natl Acad. Sci. USA 98, 5122-5127 (2001).

39. Yurieva, O. \& O'Donnell, M. Reconstitution of a eukaryotic replisome reveals the mechanism of asymmetric distribution of DNA polymerases. Nucleus 7, 360-368 (2016).

40. Ganai, R. A., Osterman, P. \& Johansson, E. Yeast DNA polymerase $\varepsilon$ catalytic core and holoenzyme have comparable catalytic rates. J. Biol. Chem. 290, 3825-3835 (2015).

41. Shcherbakova, P. V. et al. Unique error signature of the four-subunit yeast DNA polymerase $\varepsilon$. J. Biol. Chem. 278, 43770-43780 (2003).

42. Waga, S. \& Stillman, B. Anatomy of a DNA replication fork revealed by reconstitution of SV40 DNA replication in vitro. Nature 369, 207-212 (1994).

43. Pavlov, Y. I. \& Shcherbakova, P. V. DNA polymerases at the eukaryotic fork20 years later. Mutat. Res. 685, 45-53 (2010).

44. Johnson, R. E., Klassen, R., Prakash, L. \& Prakash, S. A major role of DNA polymerase $\delta$ in replication of both the leading and lagging DNA strands. Mol. Cell 59, 163-175 (2015).

45. Burgers, P. M., Gordenin, D. \& Kunkel, T. A. Who is leading the replication fork, Pol $\varepsilon$ or Pol $\delta$ ? Mol. Cell 61, 492-493 (2016).

46. Flood, C. L. et al. Replicative DNA polymerase $\delta$ but not $\varepsilon$ proofreads errors in Cis and in Trans. PLoS Genet. 11, e1005049 (2015).

47. Gary, S. L. \& Burgers, M. J. Identification of the fifth subunit of Saccharomyces cerevisiae replication factor C. Nucleic Acids Res. 23, 4986-4991 (1995).
48. Shcherbakova, P. V. \& Kunkel, T. A. Mutator phenotypes conferred by $M L H 1$ overexpression and by heterozygosity for mlh1 mutations. Mol. Cell Biol. 19, 3177-3183 (1999)

49. Goldstein, A. L. \& McCusker, J. H. Three new dominant drug resistance cassettes for gene disruption in Saccharomyces cerevisiae. Yeast 15, 1541-1553 (1999).

50. Kochenova, O. V., Daee, D. L., Mertz, T. M. \& Shcherbakova, P. V. DNA polymerase $\zeta$-dependent lesion bypass in Saccharomyces cerevisiae is accompanied by error-prone copying of long stretches of adjacent DNA. PLoS Genet. 11, e1005110 (2015).

51. Chilkova, O., Jonsson, B. H. \& Johansson, E. The quaternary structure of DNA polymerase $\varepsilon$ from Saccharomyces cerevisiae. J. Biol. Chem. 278, 14082-14086 (2003).

52. Sibenaller, Z. A., Sorensen, B. R. \& Wold, M. S. The 32- and 14-kilodalton subunits of replication protein A are responsible for species-specific interactions with single-stranded DNA. Biochemistry 37, 12496-12506 (1998)

53. Drake, J. W. A constant rate of spontaneous mutation in DNA-based microbes. Proc. Natl Acad. Sci. USA 88, 7160-7164 (1991).

54. Grabowska, E. et al. Proper functioning of the GINS complex is important for the fidelity of DNA replication in yeast. Mol. Microbiol. 92, 659-680 (2014).

\section{Acknowledgements}

We thank Erik Johansson for pJL1 and pJL6 plasmids, Peter Burgers for RFC, Krista Brown for technical assistance, and Stephanie Barbari and Youri Pavlov for critically reading the manuscript. This work was supported by the National Institutes of Health grant ES015869 and by Nebraska Department of Health and Human Services grant LB506 to PVS, and by the Swedish Cancer Society and the Swedish Research Council grants to AC. C.R.B. was supported by a University of Nebraska Medical Center Graduate Studies Research Fellowship.

\section{Author contributions}

P.V.S. conceived and supervised the study. X.X. purified Pole variants and performed all biochemical assays. D.P.K. contributed to the initial biochemical characterization of Pole variants and studied the genetic interaction with MMR deficiency. C.R.B. studied the genetic interaction with Pol $\zeta$ deficiency. D.P.K. and E.A.M characterized the mutational specificity of pol2-P301R strains. S.S. measured dNTP pools in the pol2-P301R mutants. A.C. supervised the analysis of dNTP pools. X.X. and P.V.S. wrote the manuscript, with input from all other authors.

\section{Additional information}

Supplementary Information accompanies this paper at https://doi.org/10.1038/s41467018-08145-2.

Competing interests: The authors declare no competing interests.

Reprints and permission information is available online at http://npg.nature.com/ reprintsandpermissions/

Journal peer review information: Nature Communications thanks the anonymous reviewers for their contribution to the peer review of this work. Peer reviewer reports are available.

Publisher's note: Springer Nature remains neutral with regard to jurisdictional claims in published maps and institutional affiliations.

Open Access This article is licensed under a Creative Commons Attribution 4.0 International License, which permits use, sharing, adaptation, distribution and reproduction in any medium or format, as long as you give appropriate credit to the original author(s) and the source, provide a link to the Creative Commons license, and indicate if changes were made. The images or other third party material in this article are included in the article's Creative Commons license, unless indicated otherwise in a credit line to the material. If material is not included in the article's Creative Commons license and your intended use is not permitted by statutory regulation or exceeds the permitted use, you will need to obtain permission directly from the copyright holder. To view a copy of this license, visit http://creativecommons.org/ licenses/by/4.0/

(C) The Author(s) 2019 